\title{
FORMAÇÃO CONTINUADA DE PROFESSORES DE LÍNGUAS ESTRANGEIRAS DA REDE PÚBLICA: contribuições do cinema e da Teoria da Atividade
}

\author{
Viviane Cristina Garcia de Stefani ${ }^{1}$
}

\begin{abstract}
Resumo
$\mathrm{Na}$ sociedade em que vivemos, o estreitamento do contato entre os povos e o crescente processo de internacionalização do conhecimento têm nos levado a pensar maneiras mais eficientes de aprender, de ensinar, e de aprender a ensinar um idioma estrangeiro, especialmente quando sabemos que aprender outro idioma implica abrir-se para outras culturas, outras formas de agir, pensar e ver o mundo. Tendo em vista essas questões, e considerando estudos que comprovam que o cinema é um instrumento eficaz para o ensino da língua-cultura alvo, o objetivo deste artigo é dar visibilidade aos resultados de uma investigação em nível de doutorado, acerca do uso do cinema como instrumento didático em um curso de formação continuada para professores de língua estrangeira moderna (inglês e espanhol) da rede pública de ensino, considerando que ensinar língua estrangeira por meio do cinema motiva o aprendente (HARLOW; MUYSKENS, 1994), auxilia no desenvolvimento das habilidades comunicativas (STEPHEN, 2001) e estimula o aprendizado autônomo (FIORENTINI, 2002; GARCIA-STEFANI, 2010). No curso com 30 horas de duração foram oferecidos aportes teóricos e práticos que dessem subsídios aos professores para analisarem e prepararem atividades didáticas com conteúdo fílmico. Nesse contexto, foram intensas as interações e trocas de experiências entre os cursistas, de forma que todas as atividades preparadas fossem compartilhadas e analisadas pelo grupo antes de serem aplicadas em sala de aula. Os dados obtidos por meio de questionários, notas de campo e grupo focal foram analisados à luz da Teoria da Atividade (LEONTIEV, 1978, 1981; VYGOTSKY, 1991; 1993; ENGESTRÖM, 2009, 1999), que reconhece que todos somos fonte do saber e podemos agir de forma colaborativa para ampliar a construção de sentidos. Dessa forma, os protagonistas da pesquisa foram responsáveis pela aprendizagem uns dos outros. Resultados do estudo apontam o cinema como instrumento eficaz e motivador para o ensino de línguas estrangeiras; e a troca de experiências e a interação promovida entre os professores participantes foram importantes na resolução de problemas, contribuindo, efetivamente para sua formação continuada, bem como para o ensino significativo de línguas.
\end{abstract}

Palavras-chave: formação de professores; ensino de língua estrangeira, cinema, Teoria da Atividade.

\section{FORMACIÓN CONTINUADA DE PROFESORES DE LENGUAS EXTRANJERAS DE ESCUELAS PÚBLICAS: contribuciones del cinema y de la Teoría de la Actividad}

\section{Resumen}

En la sociedad en que vivimos, el estrechamiento de las relaciones entre personas de diferentes culturas y el creciente proceso de internacionalización del conocimiento nos han llevado a pensar maneras más eficientes de aprender, de enseñar, y de aprender a enseñar un idioma extranjero, especialmente cuando sabemos que aprender otro idioma supone abrirse a otras culturas, otras formas de actuar, pensar y de estar en el mundo. Teniendo en cuenta estas cuestiones, y considerando estudios que demuestran que el cine es un instrumento eficaz para la enseñanza de lenguas-culturas extranjeras, el objetivo de este artículo es dar visibilidad a los resultados de una investigación a nivel de doctorado, acerca del uso del cine como instrumento didáctico en un curso de formación continuada para profesores de lengua

\footnotetext{
${ }^{1}$ Instituto Federal de Educação, Ciência e Tecnologia de São Paulo (IFSP), São Carlos - SP - Brasil. Docente. Doutora em Linguística. ORCID <https://orcid.org/0000-0001-9668-3106>. E-mail: vivigarciastefani@gmail.com
} 
extranjera moderna (inglés y español) de la red pública de enseñanza en Brasil, considerando que enseñar lengua extranjera a través del cine motiva al alumno (HARLOW y MUYSKENS, 1994), ayuda en el desarrollo de las habilidades comunicativas (STEPHEN, 2001) y estimula el aprendizaje autónomo (FIORENTINI, 2002; GARCIA-STEFANI, 2010). En el curso con 30 horas de duración se ofrecieron aportes teóricos y prácticos que dieran subsidios a los profesores para analizar y preparar actividades didácticas con contenido fílmico. En ese contexto, fueron intensas las interacciones e intercambios de experiencias entre los participantes, de manera que todas las actividades preparadas fueran compartidas y analizadas por el grupo antes de ser aplicadas en la clase. Los datos obtenidos por medio de cuestionarios, notas de campo y grupo focal fueron analizados a la luz de la Teoría de la Actividad (LEONTIEV, 1978, 1981; VYGOTSKY, 1998; ENGESTRÖM, 2009, 1999a), que reconoce que todos somos fuente del saber y podemos actuar de forma colaborativa para ampliar la construcción de sentidos. De esta forma, los protagonistas de la investigación fueron responsables por el aprendizaje unos de los otros. Los resultados del estudio apuntan el cine como un instrumento eficaz y motivador para la enseñanza de lenguas extranjeras; y el intercambio de experiencias y la interacción entre los profesores participantes fueron importantes en la resolución de problemas, contribuyendo, efectivamente, para su formación continuada, así como para la enseñanza significativa de lenguas.

Palabras clave: Formación de profesores, enseñanza de lengua extranjera, cinema, Teoría de la Actividad.

\title{
CONTINUING EDUCATION FOR FOREIGN LANGUAGE TEACHERS FROM PUBLIC SCHOOLS: contributions from the cinema and from the Activity Theory
}

\begin{abstract}
In the society where we are living, the closer contact between peoples and the growing process of internationalization of knowledge have led us to think of more efficient ways of learning, teaching, and learning how to teach a foreign language, especially when we know that learning a foreign language implies opening up to other cultures, other ways of acting, thinking and being in the world. Considering these issues, and considering studies that have proved that cinema is an effective instrument for teaching the target language-culture, the objective of this article is to give visibility to the results of a doctoral-level research about the use of cinema as educational tool in a continuing education course for foreign language teachers (English and Spanish) from public schools in Brazil. We assume that teaching a foreign language through films motivates the learner, assists in the development of communication skills and stimulates the autonomous learning. In the period of the course (30 hours) we could offer theoretical support to help the teachers to analyze and prepare teaching activities with filmic content. Besides the theoretical assistance, we offer opportunities for interaction and exchange of experience among the participants, so all the prepared activities could be shared and analyzed by the group before being applied in the classroom. The data obtained through questionnaires, field notes and focal groups were analyzed based on the Activity Theory, recognizing that we are all a source of knowledge and we can act collaboratively to expand the construction of meaning. Thus, the protagonists of the research were responsible for each other's learning. The results of the study indicate that the cinema is a motivating and efficient tool for teaching foreign languages, and the exchange of experiences and interaction fostered among teachers were important in solving problems, contributing effectively to their education, as well as to a significant foreign language teaching.
\end{abstract}


Keywords: Teachers Education, Foreign Language Teaching, Cinema, Activity Theory

\section{Introdução}

A importância educativa do cinema tem sido cada vez mais reconhecida, tanto por parte de pesquisadores e professores quanto das administrações públicas, especialmente nas últimas décadas.

Desde a década de 1930 no Brasil o governo federal e alguns governos estaduais têm tentado estabelecer o cinema como instrumento auxiliar no processo educacional ${ }^{2}$, embora sem sucesso. Alguns projetos parecem ousados e inovadores, no entanto, não conseguem consolidar as relações entre o cinema e a educação, nem fortalecer a formação docente no uso do cinema (CIPOLINI, 2008).

O fato de projetos como esses - com o intuito de inserir o cinema na prática pedagógica - não emplacarem, nos intriga, especialmente quando esse recurso é comprovadamente eficaz no processo de ensino e aprendizagem, segundo estudiosos do tema. Provavelmente isso ocorre devido ao fato de que a preocupação do governo ao tentar implementar esses projetos tem sido mais voltada em equipar as escolas com aparatos tecnológicos do que em investir na formação de professores para atuarem nesse âmbito.

O trabalho com qualquer tecnologia em sala de aula - e o cinema é uma delas demanda revisão das práticas pedagógicas. Não basta equipar as escolas com os mais modernos aparatos tecnológicos; é preciso que haja um trabalho de formação docente para a utilização desses recursos, por meio do qual possam ser desenvolvidas novas práticas e abordagens de ensino.

\footnotetext{
2 a) Em 1937 o então presidente Getúlio Vargas cria o Instituto Nacional do Cinema Educativo (INCE), oficializado pela aprovação da lei 378 , artigo 40 , com o objetivo de promover e orientar a utilização do cinema como auxiliar no processo de ensino e como meio de educação popular em geral; b) no final da década de 80, a Fundação para o Desenvolvimento da Educação (FDE), do governo do estado de São Paulo, visando apoiar o trabalho do professor, cria uma biblioteca e uma videoteca, cujos acervos eram disponibilizados, sem custo, aos professores da rede pública estadual. A FDE publica, ainda, no início da década de 90 , uma coleção intitulada Lições com Cinema, reunindo textos que expõem a contribuição da arte cinematográfica nas discussões sobre temas polêmicos, estabelecendo relações interdisciplinares do cinema com literatura, história, geografia e demais disciplinas do currículo; c) em 2008 o governo do estado de São Paulo, por meio da Fundação para o Desenvolvimento da Educação, implanta o projeto O cinema vai a Escola - a linguagem cinematográfica na Educação, proposto como parte do programa Cultura é Currículo. Esse projeto visou subsidiar a rede pública de ensino com materiais, equipamentos e acervos didáticos, fornecendo às escolas de Ensino Médio um conjunto de filmes de diferentes categorias e gêneros, em DVD, acompanhado de materiais de apoio à prática pedagógica, com o objetivo de facilitar o acesso dos alunos a produções cinematográficas que contribuam para a formação crítico-reflexiva do jovem e do adulto, para a ampliação do seu repertório cultural, e para o diálogo entre o currículo escolar e as questões socioculturais mais amplas.
} 
Programas de formação docente que utilizem Tecnologias de Informação e Comunicação (TIC) ${ }^{3}$, como é o caso do cinema (NAPOLITANO, 2003), são fundamentais no atual cenário da educação, e vão ao encontro das recomendações da $\operatorname{UNESCO}^{4}$ (2004), que enfatizam a importância de docentes e futuros docentes se formarem e atuarem em ambientes educativos que façam uso inovador das tecnologias.

O estudo desenvolvido objetivou investigar de que maneira a inserção do cinema como recurso didático poderia contribuir para o processo de ensino e aprendizagem de línguas estrangeiras.

\section{O cinema como recurso didático}

Ao nos propormos a contribuir para que professores de língua estrangeira moderna da rede pública utilizem o cinema como ferramenta didática para o ensino do idioma, partimos da premissa de que essa ferramenta auxilia a viabilização de um ensino significativo, considerando o resultado de diversas pesquisas sobre o tema. Estudos indicam vantagens da utilização do cinema como ferramenta de ensino-aprendizagem de LE, pelo fato de que o filme atua como: 1) material didático autêntico (CRUZ, SOUZA, LIMA, 2006); 2) material lúdico (NAPOLITANO, 2003); 3) elemento contextualizador da língua estrangeira (LE) (STEPHENS, 2001); 4) agente motivador do aprendizado (CRUZ, SOUZA, LIMA, 2006; GARCIA-STEFANI, 2010; TORRECILLAS, SÁNCHEZ, 1993; PÉREZ TOBARRA, 2007); 5) fomentador do trabalho com as Tecnologias de Informação e Comunicação (TICs) em sala de aula (NAPOLITANO, 2003; GOYES NARVÁES, 2002); 6) estímulo para pesquisas extraclasse (GARCIA-STEFANI, 2010); 7) forma inovadora de ensinar (NAPOLITANO, 2003); 8) fonte de percepção de diferentes linguagens (STEPHENS, 2001); 9) vitrine de situações verossímeis de comunicação (ALMEIDA, 2000); 10) encorajador do uso da línguaalvo (GARCIA-STEFANI, 2010); 11) facilitador do desenvolvimento de habilidades linguístico-culturais (STEPHENS, 2001); 12) propulsor do desenvolvimento da autonomia na aquisição de LE (GARCIA-STEFANI, 2010; CRUZ, SOUZA e LIMA, 2006); 13) veículo

\footnotetext{
${ }^{3}$ Considerando as múltiplas definições que encontramos do termo Tecnologias da Informação e Comunicação (TIC), esclarecemos que, neste estudo, esse termo é utilizado para designar todos os recursos tecnológicos que interferem e medeiam os processos informacionais e comunicativos dos seres. Consideramos o cinema como sendo um desses recursos (NAPOLITANO, 2003).

${ }^{4}$ UNESCO (United Nation Educational, Scientific and Cultural Organization - Organização para a Educação, a Ciência e a Cultura das Nações Unidas), organismo integrado na Organização das Nações Unidas (ONU), criado em 1946.
} 
para trabalhar a interdisciplinaridade (GARCIA-STEFANI, 2010); 14) facilitador da compreensão de mundo (MIRANDA, COPPOLA e RIGOTTI, 2005); 15) ferramenta na formação crítica de professores de línguas (MAYRINK, 2007) 5 .

Como vemos, a "sétima arte" vai muito além do entretenimento - ela pode atuar como um poderoso instrumento de ensino e aprendizagem significativos. Destacamos aqui, o fato de que o cinema favorece a abordagem de aspectos interculturais e o trabalho com a interdisciplinaridade na sala de aula - tão recomendados pelos documentos que orientam o ensino de língua estrangeira moderna no país:

[...] nos programas pedagógicos são reforçadas as propostas de interdisciplinaridade, transdisciplinaridade, transversalidade. O intuito delas é promover a expansão da compreensão de mundo, pois pretendem ensinar os alunos a entender as relações entre as disciplinas pedagógicas - em vez de ensinar as matérias escolares de maneira isolada, ou seja, voltadas para si mesmas - e as disciplinas escolares, e delas com a sociedade e a vida dos alunos. O resultado esperado deve reverter para a compreensão da complexidade social em que vivem os cidadãos (no caso, alunos, professores, pais, familiares), sendo a questão da diversidade um dos componentes dessa complexidade. $\left(\mathrm{OCEM}^{6}\right.$. p. 94)

[...] com o tema intertextualidade e cinema, são propostas atividades de análise de filmes, programas de televisão, propagandas e excertos de textos literários. Essas atividades levam os alunos a discussões relevantes para sua formação ética, promovendo a reflexão sobre estereótipos, preconceito e consumo.

(Currículo do Estado de SP/ Língua Estrangeira Moderna, 2010, p. 108-109)

$\mathrm{Na}$ aula de língua estrangeira, o cinema favorece o trabalho interdisciplinar e o ensino de cultura principalmente porque atua como uma vitrine de situações de interação entre falantes do idioma. Por meio dessa "vitrine" podemos observar diferentes aspectos que envolvem o "agir" no idioma-alvo, expandindo, dessa forma, nossa compreensão de mundo e da complexidade social presente nas mais diversas comunidades de prática ${ }^{7}$ (WENGER, 1998; GEE, 2004, 2009) que ali são retratadas.

\footnotetext{
${ }^{5}$ Os resultados dos estudos dos autores citados podem ser encontrados no trabalho de GARCIA-STEFANI, 2010, p. 59-67, que traça um breve panorama sobre as pesquisas referentes ao uso do cinema com fins educativos.

${ }^{6}$ OCEM: Orientações Curriculares para o Ensino Médio (BRASIL, 2010).

${ }^{7}$ Neste trabalho, o termo "Comunidades de Prática" é usado tal como é definido por Wenger (1998), como um sistema de auto-organização no qual um grupo de pessoas, com objetivos comuns, engaja-se em torno de atividades ou empreendimentos; se organizam em torno de determinadas áreas de conhecimento e atividades particulares que dão aos membros um sentido de associação, de vida coletiva, engajamento e identidade. Para a autora, "Comunidades de prática" é sinônimo de "Comunidades de Aprendizagem", pois se refere ao processo de aprendizagem social em que as pessoas agem de forma engajada para encontrar soluções e construir inovações para problemas de interesse comum (WENGER, 1998). Nos filmes, as diversas comunidades de prática ali retratadas apenas simulam as reais comunidades de prática da vida cotidiana coletiva.
} 


\section{O cinema na perspectiva da Teoria da Atividade}

Os pressupostos da Teoria da Atividade (TA) ${ }^{8}$ (LEONTIEV, 1978a; VYGOTSKY, 1920; 1988; LURIA e YODOCICH, 1985; VYGOTSKY, LURIA e LEONTIEV, 1988) também nos auxiliam a compreender o papel do cinema como uma ferramenta eficaz para o ensino de idiomas, bem como sua importância na interação entre professores de LE. A TA prevê que aprendizagem e desenvolvimento ocorrem na interação entre um sujeito e outro, mas não ocorrem diretamente, e sim através de um processo de mediação ${ }^{9}$, com o uso obrigatório de um determinado instrumento, que pode ser a própria língua ou algum artefato social como o livro, o computador, o cinema.

Daniels $(2002 ; 2004)$ ao escrever sobre os estudos de Vygotsky, fundamentalmente no que diz respeito à Teoria da Atividade, explica que o conhecimento é socialmente construído por esforços colaborativos para atingir objetivos compartilhados em ambientes culturais, e a informação é processada entre indivíduos, ferramentas e artefatos fornecidos pela cultura.

Sob essa perspectiva, o cinema atua como artefato cultural que auxilia os envolvidos no processo de ensino-aprendizagem a processar a informação necessária na atividade de adquirir língua estrangeira.

A TA vê a ferramenta como um processo de mediação entre o sujeito e o objeto do conhecimento, além de dar conta do processo de interação entre os sujeitos e os demais componentes do contexto no qual está inserido (LEFFA, 2005).

O cinema, neste estudo, é a ferramenta que atua como artefato cultural mediacional estimulando o sujeito na aquisição e produção do conhecimento ${ }^{10}$, em um cenário criado para possibilitar autorreflexão, negociação de sentidos e interpretações, além de estabelecimento de conflitos entre as ações práticas e teóricas.

\footnotetext{
${ }^{8}$ A TA é uma teoria da práxis ${ }^{8}$ orientada pelo princípio dialético em que aprendizagem e desenvolvimento são processos integrados, em que reflexão, desejo e ação humana se interligam. Na ocasião de seu surgimento (década de 20), pensadores como Leontiev (1978a, 1981), Vygotsky (1920, 1934, 1978, 1988, 1991a, 1993b) e Luria $(1985,1990,1992,1999)$ estudavam o desenvolvimento humano por meio da ação de homens e mulheres no mundo, objetivando transformações das relações de desigualdade e de opressão sociais.

9 O termo "mediação" está sendo usado neste trabalho de acordo com o conceito vygotskyano, que o define como o processo que caracteriza a relação do homem com o mundo e com outros homens (BERNI, 2006, p. 2539). Para Vygotsky é no processo de mediação que as Funções Psicológicas Superiores (FPS), tipicamente humanas, se desenvolvem.

${ }^{10}$ Nesse caso, a produção de conhecimento se refere ao ensino-aprendizagem de língua estrangeira de maneira significativa.
} 
De acordo com Vieira-Abraão (2012), os artefatos mediacionais são construídos culturalmente pelos seres humanos para regular o mundo (ou seu próprio mundo) e suas atividades sociais e mentais (VIEIRA-ABRAÃO, 2012, p.5).

A Teoria da Atividade envolve, ainda, a noção de agentividade relacional (EDWARDS, 2009), que é a capacidade de trabalhar com os outros para promover a expansão do pensamento e tentar transformar pelo reconhecimento, análise e exploração das experiências que os outros trazem, na medida em que reinterpretam essas experiências (MATEUS; KADRI, 2012). Significa reconhecer que todos somos fonte do saber e podemos agir de forma colaborativa para ampliar a construção de sentidos. Essa ideia foi a mola propulsora do curso de formação continuada.

\section{O curso de formação continuada para o trabalho com cinema}

Para viabilizar a formação de professores de língua estrangeira da rede pública para o uso do cinema como recurso didático, realizamos, em parceria com a Secretaria da Educação do Estado de São Paulo e com a Diretoria Regional de Ensino da Região de São Carlos/SP, um curso presencial de formação continuada com 30 horas de duração, por meio do qual professores de línguas estrangeiras da rede pública puderam habilitar-se para analisar, desenvolver e aplicar material didático com conteúdo fílmico em suas salas de aula. $\mathrm{O}$ resultado do curso de formação, incluindo o processo de análise, desenvolvimento e aplicação das atividades didáticas serviu como base de dados para a pesquisa.

O curso de formação continuada objetivou: 1) criar um espaço para construção de novas práticas docentes; 2) incentivar professores de línguas estrangeiras a utilizar o cinema como ferramenta de ensino; 3) auxiliar os participantes nas atividades de análise e elaboração de atividades didáticas com conteúdo fílmico; 4) promover ambiente de troca de experiências entre professores; 4) promover reflexões sobre práticas pedagógicas inovadoras; 5) promover reflexões sobre o processo de ensino e aprendizagem de línguas.

Houve 17 inscritos (13 mulheres e 04 homens), todos professores de línguas estrangeiras de escolas públicas (09 professores de inglês; 09 professores de espanhol; 04 professores de português, 01 professora de alemão e 02 professoras de italiano ${ }^{11}$ ).

Para o curso de preparação de atividades didáticas foram selecionados seis filmes (três de língua inglesa e três de língua espanhola), todos do projeto "O cinema vai à escola", da

\footnotetext{
${ }^{11} \mathrm{O}$ número de professores mencionados ultrapassa o número total de inscritos no curso, considerando que é comum que lecionem mais de um idioma na escola.
} 
Secretaria Estadual de Educação - projeto que, de certo modo, fundamentou e justificou nosso trabalho de caráter interventivo, considerando que se trata de um projeto grande, que demandou muito investimento, mas, no entanto, não foi promovido por parte do governo um trabalho efetivo de formação continuada dos professores para sua implantação ${ }^{12}$. Por meio desse projeto, foi disponibilizada às escolas estaduais, desde 2008, uma coleção de 80 filmes, bem como cadernos de orientação para o professor. Optamos por eleger os filmes do projeto por se tratar de um material já disponível nas escolas públicas de ensino médio do estado de São Paulo, de fácil acesso aos professores. Todos os seis filmes têm como tema central a pluralidade cultural. Priorizamos os filmes com essa temática pelo interesse em trabalhar questões culturais a partir do cinema. São eles: Gran Torino, Em Busca da Terra do Nunca; Um Beijo Roubado (inglês); A Língua das Mariposas, Donkey Xote e Diários de Motocicleta (espanhol). Dos seis filmes indicados, os professores deveriam escolher quatro, com os quais desejariam trabalhar. Os quatro selecionados foram: Gran Torino; Em Busca da Terra do Nunca; A Língua das Mariposas; e Donkey Xote. Trabalhamos, ainda com um filme italiano e um alemão (Cinema Paradiso e $A$ Onda $)^{13}$.

No curso de formação continuada, proporcionamos suporte teórico que auxiliasse os professores na análise, desenvolvimento e aplicação de atividades didáticas (ADs) com conteúdo fílmico, e também oferecemos condições para que, na interação com os demais colegas, os conteúdos dessas atividades pudessem ser discutidos conjuntamente antes de serem aplicados em sala de aula.

Para promover a interação entre os professores na elaboração das atividades didáticas e o compartilhamento de experiências sobre possíveis abordagens na sua execução, foi imprescindível que o curso tivesse caráter presencial.

Embora muitos cursos de formação continuada para professores da rede pública estejam sendo oferecidos, preferencialmente à distância, optamos por realiza-lo de modo

12 A informação de que não houve um trabalho efetivo de formação continuada de professores para a implantação do projeto foi obtida diretamente na Secretaria de Educação do Estado de São Paulo, quando entramos em contato com um dos responsáveis pela implantação do projeto "O Cinema vai à Escola". Na ocasião foi-nos informado de que a Secretaria e Educação promove oficinas de treinamento com representantes das diretorias de ensino e que cada diretoria é responsável pela divulgação e implementação do projeto na região de alcance. Na página Web do projeto (http://culturaecurriculo.fde.sp.gov.br/Cinema/Cinema.aspx) também é possível verificar que não constam informações sobre qualquer trabalho que tenha sido feito junto aos professores da rede pública estadual para que utilizassem os filmes do projeto em sala de aula. Nela constam apenas alguns depoimentos de professores que trabalharam atividades isoladas em suas respectivas escolas. Esses depoimentos podem ser lidos na sessão "registre sua experiência".

13 Os filmes de italiano (Cinema Paradiso) e alemão ( $A$ Onda) não estavam previstos no início do curso. No entanto, professoras desses idiomas que se inscreveram no curso manifestaram desejo de utilizá-los, e a professora-pesquisadora não fez nenhuma objeção, passando a integrá-los no material com conteúdo fílmico que estava sendo elaborado pelos professores cursistas. 
presencial, considerando que a modalidade à distância tem sido alvo de críticas por parte dos professores, uma vez que as situações de interação nesse tipo de curso são bastante limitadas. Entendemos que, se o oferecêssemos na modalidade à distância, as trocas de experiências, o compartilhamento de ideias e o esclarecimento de dúvidas também estariam restritos. Era desejável que houvesse um clima de confiança, empatia ${ }^{14}$ e afetividade entre os envolvidos, para que pudessem sentir-se confortáveis na condição de criticar e de receber críticas sobre as atividades didáticas que desenvolveriam a partir de conteúdo fílmico, e esse clima seria mais facilmente construído em ambiente presencial.

Além da construção de um ambiente favorável de empatia e afetividade entre os professores participantes, era fundamental que o curso de formação que estávamos nos propondo a ministrar não reproduzisse situações tradicionais de muitas salas de aula, em que o professor constitui aquele que sabe, e o aluno aquele que não sabe, cabendo àquele ensinar, e a este, aprender (UYENO, 2002, p. 20). O papel da professora-pesquisadora-formadora deveria ser, naquele contexto, o de prover aos participantes subsídios teóricos necessários para o desenvolvimento de material didático com conteúdo fílmico, além de promover condições para pudessem agir criticamente a partir da teoria e da prática da teoria. Ao terem a oportunidade de desenvolver material didático em situações interativas, de aplica-lo em suas respectivas salas de aula, e de poder compartilhar com os colegas o resultado da aplicação, os professores cursistas poderiam ter um retorno sobre o resultado do trabalho desenvolvido durante todo o curso de formação.

O modelo desejável de formação continuada dá um novo lugar para a prática - como locus de construção e não somente de aplicação de teoria (MAGALHÃES, 2002). Trata-se, portanto, de um espaço onde se possa refletir sobre a prática pedagógica e incorporar novas práticas. Viabilizar esse espaço de formação é garantir ao professor o direito de, diante de determinadas situações, trabalhar contra concepções tradicionalmente estabelecidas pela cultura da instituição escolar; é estimulá-lo a conhecer o contexto em que atua e as necessidades de seus alunos, dando-lhe o poder de tomar decisões com base nesses conhecimentos.

Para orientar os professores participantes na elaboração das atividades didáticas, nos baseamos nos princípios do aprendizado propostos por GEE (2004), os quais também consideramos ao embasarmos teoricamente o curso de formação continuada. Segundo o autor,

\footnotetext{
14 O termo Empatia é usado neste estudo com o sentido de aptidão para identificar-se com o outro, para enxergar-se de acordo com a opinião de outra pessoa, enxergar os outros de acordo com a opinião de outra pessoa; e enxergar os outros de acordo com a opinião deles próprios. (termo usado na sociologia).
} 
para promover o aprendizado, as atividades desenvolvidas em sala de aula devem: 1) estimular a prática da língua-alvo; 2) estimular a interação entre os alunos (clima de colaboração e compartilhamento); 3) promover a livre-expressão individual; 4) estimular o aprendizado autônomo; 5) simular situações da vida real; 6) estimular a realização de pesquisas extraclasse; 7) estimular a participação dos alunos na explicitação de regras gramaticais; 8) tolerar o erro; 9) promover diferentes maneiras de comunicar a mesma ideia (diferentes estratégias de comunicação); 10) promover "recompensas" pela execução das atividades; 11) favorecer a superação de dificuldades; 12) envolver as habilidades de escrita, leitura, audição e fala; 13) atentar para linguagem não verbal como forma de comunicação; 14) trabalhar com diversos gêneros textuais.

Durante o curso de formação, antes de iniciarem o processo de desenvolvimento de atividades didáticas, foi feito um trabalho de análise de atividades já desenvolvidas, dos materiais com os quais os docentes já trabalhavam. A análise levou em consideração o seguinte roteiro, desenvolvido pela professora-pesquisadora:

Roteiro para análise de atividades didáticas

1) A atividade estimula a prática da língua-alvo? De que forma?

2) Qual habilidade é focada? (escutar, falar, ler ou escrever)?

3) A atividade prioriza o uso ou a estrutura da língua?

4) De que forma a gramática é tratada? (o aluno deve reproduzir automaticamente estruturas gramaticais ou é desafiado a refletir sobre seu uso?)

5) Essa atividade é significativa para o contexto de ensino no qual eu atuo?

6) Contribui para o desenvolvimento da competência comunicativa dos alunos?

7) Faz uso de conteúdos relacionados à vida e aos interesses dos alunos?

8) Estimula a interação entre os alunos (clima de colaboração e compartilhamento)?

9) Promove a livre-expressão individual?

10) Estimula o aprendizado autônomo do aluno?

11) Estimula a realização de pesquisas extraclasse?

12) Estimula a participação dos alunos na explicitação de regras gramaticais?

13) Tolera o erro?

14) Promove diferentes maneiras de comunicar a mesma ideia (diferentes estratégias de comunicação)?

15) Promove reflexão?

16) Favorece a superação de dificuldades?

17) Trabalha com gêneros textuais?

18) Utiliza textos autênticos para criar interesse e fornecer modelos válidos de uso da língua? Quadro 1: Roteiro para análise de atividades didáticas (GARCIA-STEFANI, 2015, p. 103)

O trabalho de análise de ADs foi desenvolvido no intuito de auxiliar os professores na preparação de seu próprio material. Também nessa perspectiva, oferecermos durante o curso de formação, um modelo de atividades didáticas com conteúdo fílmico, disponibilizamos um resumo com alguns exemplos de procedimentos didáticos (GARCIA DE STEFANI, 2010), 
contendo 23 tipos de atividades, entre elas: 1) Comentários sobre fragmentos de diálogos previamente selecionados; 2) Elaboração de diálogos a partir da exibição de uma cena sem áudio e sem legenda; 3) Comparação com diálogos de outros filmes; 4) Dedução do significado de palavras específicas a partir do contexto em que estão inseridas; 5) Observação e reprodução de situações de saudação, apresentação e despedida em diferentes âmbitos e contextos, atentando para a linguagem verbal e não-verbal; 6) Pesquisa sobre palavras heterossemânticas; 7) Observação e comparação de ditos populares; 8) Discussão sobre os costumes de diferentes povos a partir da exibição da cena e de posteriores investigações; 9) Reflexão sobre o uso de determinados tempos verbais em situações de comunicação; 10) Leitura e discussão de parte da obra na qual o filme foi baseado; 11) Identificação de expressões usadas ao convidar para dançar, jantar etc. e aferição de outras ocasiões em que as mesmas expressões poderiam ser usadas; 12) Previsão de acontecimentos seguintes aos da cena exibida; 13) Identificação de outros idiomas falados no filme; 14) Promoção de debates sobre assuntos polêmicos suscitados pelas cenas; 15) Analogia entre o ocorrido na cena e fatos da vida pessoal do aprendente; 16) Organização de diálogos distribuídos em partes aleatórias; 17) Discussão sobre aspectos sóciopolíticos no contexto histórico do filme em comparação com o contexto atual brasileiro; 18) Análise sobre diferentes formas de celebração e comemoração na cultura alvo e materna; 19) Analogia entre imagens e textos; 20) Atividade com a trilha sonora do filme; 21) Atividade com os "extras" do filme; 22) Dramatização de cena; 23) Elaboração e publicação (na internet) de uma crítica sobre o filme.

A ideia de disponibilizar o quadro com exemplos de procedimentos didáticopedagógicos com conteúdo fílmico não era influenciar os professores a reproduzir esses procedimentos e sim, inspirá-los a criar outros a partir destes. Tratava-se somente de um ponto de partida, já que os participantes relataram não ter tido experiência prévias de desenvolvimento de material didático para o ensino de língua estrangeira.

\section{Procedimentos para preparação das atividades}

Após a seleção dos filmes a partir dos quais seriam desenvolvidas as atividades, a professora-pesquisadora entregava aos professores participantes do curso a primeira cena do filme (geralmente contendo de 5 a 10 minutos) transcrita no idioma original ${ }^{15}$.

\footnotetext{
${ }^{15}$ As transcrições foram feitas pela professora-pesquisadora-formadora.
} 
O grupo assistia à cena do filme em questão ${ }^{16} \mathrm{e}$ em seguida se reunia em pares, dando início à preparação das atividades.

No encontro seguinte à preparação das atividades, as duplas apresentavam apresentar ao grupo os exercícios preparados, bem como suas intenções ao prepará-los (contexto de aplicação, público-alvo, nível, habilidade priorizada etc.). Essas atividades eram projetadas, de forma que todo o grupo as visualizasse e pudesse opinar a respeito de sua eficácia ou não. Todos opinavam sobre as atividades, e assim contribuíamos para criar um clima de interação, troca de experiências e cumplicidade entre os participantes. Ao final das discussões sobre o conteúdo das atividades didáticas, os professores cursistas deveriam reelaborar as atividades segundo as orientações da professora-pesquisadora e dos demais colegas, antes de aplicá-las em sala de aula. Havia, ainda, a possibilidade de um professor aplicar a atividade do outro ${ }^{17}$, caso considerasse mais relevante para seu contexto de ensino.

A figura a seguir ilustra e resume as ações do curso de formação continuada:

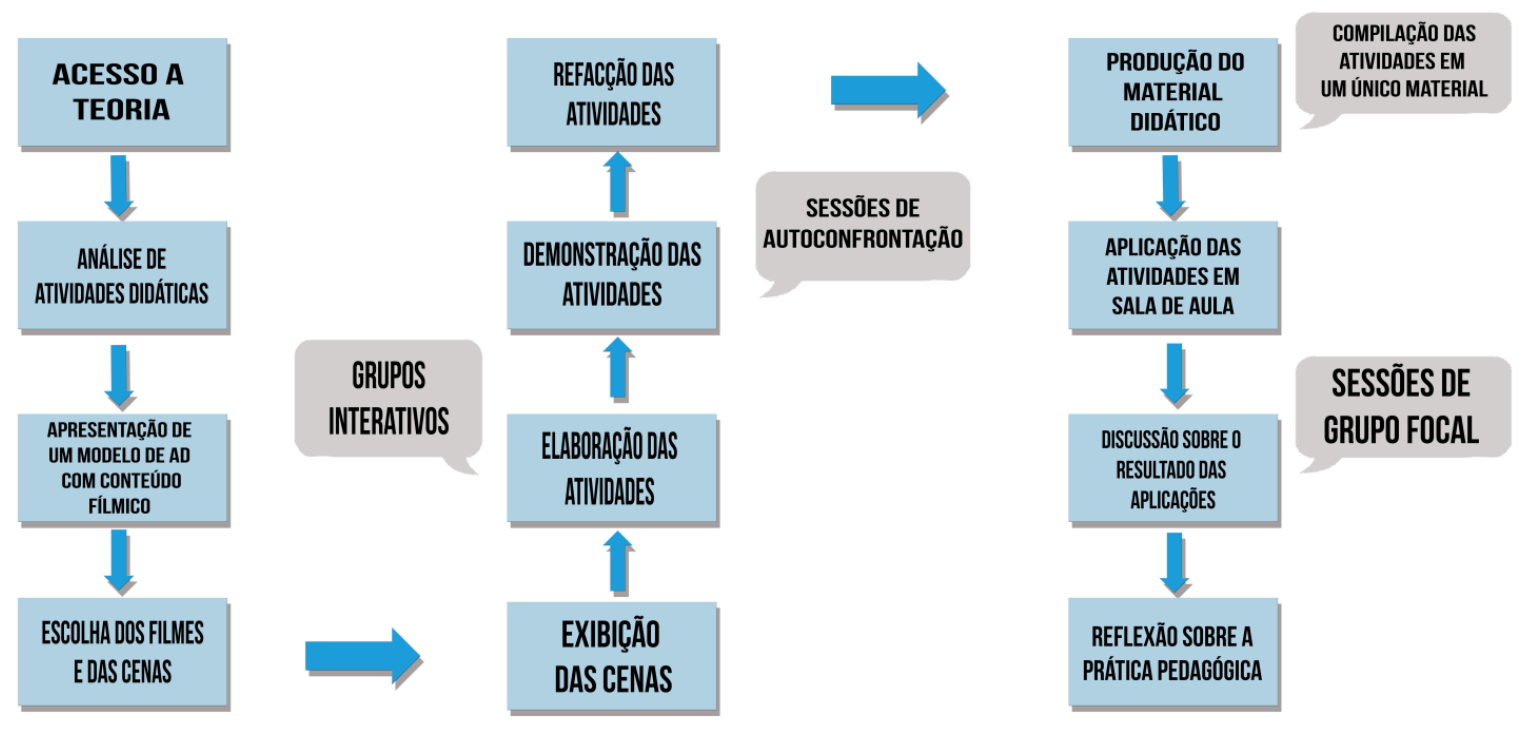

Quadro 2 - Ações do curso de formação continuada (GARCIA-STEFANI, 2015, p. 108)

A figura retrata as ações desenvolvidas durante o curso de formação continuada. Inicia-se o processo com discussões teóricas que servirão como subsídios para análise e elaboração das atividades com conteúdo fílmico. Para dar início ao processo de elaboração dos exercícios didáticos, os professores participantes recebem a cena transcrita e iniciam, em

\footnotetext{
16 Todos os participantes do curso, independentemente do idioma que lecionam, assistiam a todas as cenas, dos dois filmes, tanto em inglês quanto em espanhol. Também recebiam as cenas transcritas no original dos dois idiomas (inglês e espanhol).

${ }^{17}$ Todos os professores autorizaram, previamente, esse procedimento.
} 
duplas e/ou grupos a preparação das tarefas a serem executadas pelos alunos em sala de aula. Finalizada essa etapa, antes de aplicar a atividade em sala de aula, os professores cursistas, demonstram o resultado de seu trabalho nas sessões de autoconfrontação (CLOT, 2007). Nesse momento todos os participantes, incluindo a professora-pesquisadora, opinam sobre mudanças que podem ser necessárias antes da aplicação. Inicia-se, então, o processo de refacção dos exercícios. Após a reelaboração, os professores aplicam as atividades em sala de aula. No encontro seguinte, discutimos os resultados da aplicação nas sessões de grupo focal $^{18}$, considerando que a partir do compartilhamento de experiências e saberes, reavaliamos nossa prática pedagógica. Ao final do processo de elaboração, foi montada uma apostila compilando todas as atividades com conteúdo fílmico desenvolvidas pelos professores cursistas $^{19}$.

\section{A valorização da aprendizagem colaborativa}

Ao estudarmos os efeitos do curso de formação continuada na prática pedagógica de professores, constatamos uma grande valorização da aprendizagem colaborativa por parte dos docentes cursistas. Vivenciando a experiência da aprendizagem colaborativa em cursos presenciais de formação continuada, o professor terá mais fundamentos para propor atividades por meio das quais seus alunos também vivenciem esse processo. A Teoria da Atividade reconhece esse processo como parte da aprendizagem, ou seja, mostra-se o objetivo a que se pretende chegar, não apenas informando, mas realmente fazendo uma demonstração do que é o resultado final desejado, dando ao aluno um modelo. De certo modo, parte-se do fim para o início (LEFFA, 2005).

Os pressupostos teóricos da TA orientam na compreensão de que o domínio do instrumento é tipicamente conseguido através de um processo de tentativa e erro (LEFFA, 2005 p. 26; DUARTE, 2003). Daí a importância em permitir que os professores pudessem compartilhar uns com os outros as atividades preparadas para, quando necessário, as

\footnotetext{
${ }^{18}$ Esta técnica configura-se como uma espécie de entrevista em grupo, mas não no sentido de uma sequência de perguntas e respostas. A essência do grupo focal consiste na interação entre os participantes e o pesquisador, que objetiva a coleta de dados a partir da discussão focada em tópicos específicos e diretivos (IERVOLINO, PELICIONI, 2001). Para Iervolino e Pelicioni (2001) a coleta de dados feita por meio do grupo focal tem como uma de suas maiores riquezas "basear-se na tendência humana de formar opiniões e atitudes na interação com outros indivíduos" (p. 115).

19 A apostila com as atividades desenvolvidas pelos professores encontra-se nos anexos da tese "Formação Continuada de Professores de línguas estrangeiras mediada pelo cinema: contribuições da Teoria da Atividade ", publicada pela UFSCar em 2015, que pode ser acessada, na íntegra, no link: https://repositorio.ufscar.br/bitstream/handle/ufscar/7567/TeseVCGS.pdf?sequence=1\&isAllowed=y
} 
refazerem, seguindo as sugestões dos colegas. Esse compartilhamento de ideias permitiu, ainda, que fosse criado um clima de confiança e empatia entre os professores participantes. Leffa (2005) enfatiza que, de acordo com a TA, "há processos que só serão desenvolvidos até um nível desejado de proficiência depois de muita experimentação e prática com o instrumento" (p.26).

No início do curso, a aquisição do instrumento - a aprendizagem sobre a preparação de material de ensino com conteúdo fílmico - foi o aspecto mais importante. No decorrer do curso ocorreu uma série de ações apontavam para o fato de que o elemento mais importante passava a ser a aprendizagem colaborativa, por meio da interação. Dessa forma, o resultado do processo de aprendizagem foi além daquele inicialmente proposto (o de desenvolver a competência para a elaboração de material de ensino com conteúdo fílmico), passando a ser o de aprender por meio do compartilhamento de experiências.

Dados revelam que os professores cursistas aprendiam, a cada encontro, o quanto poderiam aprender por meio da interação. Em vários momentos do curso pudemos notar a valorização da interação e do compartilhamento de experiências, para o desenvolvimento da aprendizagem, para a aquisição do instrumento.

Os excertos que seguem, retirados dos dados obtidos por meio do relatório final dos cursistas, demonstram essa valorização:

\begin{tabular}{|l|l|}
\hline $\begin{array}{l}\text { PP8 }{ }^{20} \text { Alice } \\
\text { (relatório final) }\end{array}$ & $\begin{array}{l}\text { (...) Outro fator que julgo maravilhoso foi a troca de experiência que o curso, } \\
\text { sendo presencial, nos proporcionou. (...) aprendi também com a apresentação que } \\
\text { cada colega fez das atividades preparadas por eles. }\end{array}$ \\
\hline $\begin{array}{l}\text { PP14-Marcelo } \\
\text { (relatório final) }\end{array}$ & $\begin{array}{l}\text { Esses encontros ocorreram num total de dez semanas e nos proporcionaram uma } \\
\text { troca de experiência incrível, pois no decorrer dos encontros e das apresentações } \\
\text { das atividades, cada professor expunha suas ideias, propósito e experiências } \\
\text { adquiridas por meio das atividades elaboradas. (...) Por meio, desse curso foi } \\
\text { possível elaborar e aprender um com o outro a rever se suas atividades são } \\
\text { pertinentes e se o conteúdo exigido pelo professor corresponderia ao público alvo. }\end{array}$ \\
\hline PP17- Mônica & $\begin{array}{l}\text { O olhar dos colegas com sugestões, também foi interessante (...), foi muito } \\
\text { enriquecedor e produtivo.(..) Com a interação com os colegas e troca de } \\
\text { experiência, temos outra maneira de focar as atividades. (...) Depois da troca de } \\
\text { experiência nos sentimos mais preparados para elaborar atividades a partir de } \\
\text { (relatório final) } \\
\text { filmes (...) a expectativa foi superada, (...) tivemos aporte dos colegas de trabalho, } \\
\text { (...) a participação foi efetiva e colaborativa. }\end{array}$ \\
\hline $\begin{array}{l}\text { (PP 13- } \\
\text { Antonia } \\
\text { (relatório final). }\end{array}$ & $\begin{array}{l}\text { Ocorreu uma troca de experiências entre professores principalmente após a } \\
\text { aplicação das atividades desenvolvidas em sala de aula (...), aprendemos com a } \\
\text { prática que não se pode passar qualquer filme, que deve haver uma adequação } \\
\text { entre o tipo de filme passado com a maturidade dos alunos (...) O que realmente } \\
\text { contribui para a elaboração da minha atividade foi a observação da apresentação } \\
\text { das atividades dos colegas de curso (...) O filme realmente pode ser um }\end{array}$ \\
\hline
\end{tabular}

${ }^{20} \mathrm{PP}=$ Professor Participante.

${ }^{21}$ Todos os nomes de professores usados neste artigo são fictícios. 


\begin{tabular}{|l|l|}
\hline & $\begin{array}{l}\text { instrumento para o aprendizado de língua estrangeira em todos os níveis quando } \\
\text { trabalhado pelo professor }\end{array}$ \\
\hline $\begin{array}{l}\text { PP5 - Eunice } \\
\text { (relatório final) }\end{array}$ & $\begin{array}{l}\text { A troca de experiências proporcionada pelo curso contribuiu intensamente para } \\
\text { que eu pudesse também aprimorar meu senso crítico e minha criatividade para } \\
\text { elaborar atividades a partir de filmes e também para avaliar atividades didáticas } \\
\text { contidas nos materiais que trabalho. }\end{array}$ \\
\hline
\end{tabular}

O relato de Alice evidencia a importância da troca de experiências entre os professores, promovida por cursos presenciais. Essa aprendizagem colaborativa ocasionada pela interação talvez não ocorresse da mesma forma se o curso fosse ministrado à distância, como têm sido tantos outros cursos de formação continuada voltados a professores da rede pública de ensino.

Optamos por grifar os termos "troca de experiências" e "interação" para que o leitor observe quão frequentemente esses termos são usados pelos professores participantes do curso, no sentido de realmente valorizarem essas ações.

As transcrições que seguem também demonstram valorização da aprendizagem por meio da interação no curso de formação continuada:

\begin{tabular}{|c|c|}
\hline $\begin{array}{l}\text { PP3 } \\
\text { Aparecida } \\
\text { (relatório final) }\end{array}$ & $\begin{array}{l}\text { Quando iniciei o curso pensei que iria receber um montão de formulinhas } \\
\text { prontas e materiais com atividades para desenvolver com minhas turmas.(...) Nós } \\
\text { criamos uma situação de aprendizagem a partir desses materiais e levamos para } \\
\text { o curso para socializarmos com os demais cursistas. Este momento foi muito } \\
\text { enriquecedor, pois tivemos o acesso às ideias de nossos colegas e assim pudemos } \\
\text { complementar a nossa atividade. (...) Esse momento de trocas de experiências } \\
\text { foi o mais enriquecedor, pois a cada trabalho apresentado nos surgiam novas } \\
\text { ideias. }\end{array}$ \\
\hline
\end{tabular}

Como vemos, a expectativa inicial de Aparecida (e da maioria dos professores participantes ${ }^{22}$ ) era receber algo pronto para ser aplicado. Isso reflete a estrutura alienada da divisão do trabalho. É como o operário que só aperta o parafuso na montagem de carros, por exemplo. O professor, em muitos casos, é levado apenas a reproduzir, aplicar o material que recebe, sem refletir sobre ele. Não lhe é dado o poder de decidir sobre esse material, e menos ainda, o poder de elaborá-lo. Não lhe são dadas, ainda, as condições necessárias para poder adaptá-lo de acordo com diferentes contextos de ensino.

Percebe-se, no excerto, que Aparecida reconhece a criação de um espaço de aprendizagem interativa. Os excertos que seguem também ilustram depoimentos dos

\footnotetext{
${ }^{22}$ De acordo com dados obtidos por meio de questionário, aplicado antes do início do curso.
} 
professores cursistas que elevam o grau de importância da aprendizagem por meio da interação, da troca de experiências:

\begin{tabular}{|l|l|}
\hline $\begin{array}{l}\text { PP 16 } \\
\text { Celina }\end{array}$ & $\begin{array}{l}\text { O que me agradou muito no curso foi poder ouvir as experiências positivas dos } \\
\text { colegas, o efeito que as atividades provocaram em alunos até então } \\
\text { desinteressados. Isso me motivou, me deu esperança de procurar superar as } \\
\text { dificuldades e assim também poder fazer a diferença na vida de meus alunos. }\end{array}$ \\
\hline $\begin{array}{l}\text { PP5 } \\
\text { Eunice } \\
\text { (relatório final) }\end{array}$ & $\begin{array}{l}\text { A troca de experiências proporcionada pelo curso contribuiu intensamente para } \\
\text { que eudesse também aprimorar meu senso crítico e minha criatividade para } \\
\text { contidas nos materiais que trabalho. }\end{array}$ \\
\hline $\begin{array}{l}\text { PP1 Ana } \\
\text { (relatório final) }\end{array}$ & $\begin{array}{l}\text { (..) É importante haver uma troca de informações entre os professores, porque } \\
\text { além de ajudar a melhorar um trabalho já preparado, os outros podem ter novas } \\
\text { ideias de como se trabalhar (..) }\end{array}$ \\
\hline $\begin{array}{l}\text { PP12 } \\
\text { Rosa } \\
\text { (relatório final) }\end{array}$ & $\begin{array}{l}\text { Durante as aulas do curso, nós docentes, interagimos constantemente, tornando } \\
\text { o curso mais dinâmico e sempre ativando a prática pedagógica. (...) Nessa } \\
\text { perspectiva, aprendi que para elaborar atividades com filmes é possível } \\
\text { desenvolver inúmeras possibilidades de trabalho. (...) Foi fundamental os } \\
\text { docentes, durante o curso, compartilharem suas experiências, promovendo } \\
\text { desta forma mais reflexão e aprendizagem. (...) A aprendizagem adquirida } \\
\text { durante as aulas do curso tornou-se efetiva, quando apliquei as atividades para os } \\
\text { alunos na escola, onde trabalho. }\end{array}$ \\
\hline
\end{tabular}

Como vemos nos fragmentos transcritos, na visão dos professores-participantes, os principais argumentos para justificar a importância da aprendizagem colaborativa no curso de formação continuada foram: 1) aumento das possibilidades de trabalhar uma gama maior de exercícios didáticos; 2) incentivo para superar dificuldades; 3) aumento do interesse dos alunos nas aulas de língua estrangeira; 4) incentivo da reflexão sobre a prática pedagógica.

Nos momentos de aprendizagem colaborativa, os professores cursistas também puderam constatar que o trabalho com cinema em sala de aula não necessita ficar restrito apenas ao filme.

\begin{tabular}{|l|l|}
\hline Trecho das notas & $\begin{array}{l}\text { Alice questiona se poderia "sair da cena do filme", trabalhar outros conteúdos.. } \\
\text { de campo da }\end{array}$ \\
professora- & como gírias, postaria de usar o filme para trabalhar questões de linguagem, \\
pesquisadora & essa a ideia! Que o filme poderia ser uma maneira de introduzir o assunto em \\
(aula 4) & sala de aula, e que em momento algum deveríamos, obrigatoriamente, "ficar \\
& $\begin{array}{l}\text { presos" nele. A ideia de Alice em trabalhar gírias é trazer para a sala de aula } \\
\text { situações de uso real da língua, mostrar que gírias são bastante usadas nas } \\
\text { situações informais de comunicação. Marcelo comenta que na comunicação } \\
\text { não existe certo ou errado, e sim adequado ou inadequado. }\end{array}$ \\
\hline
\end{tabular}

Ao preparar os professores de língua estrangeira para utilizar o cinema como ferramenta de ensino, é importante fomentar a percepção de que o filme pode ser apenas o 
estopim para o trabalho com outros conteúdos. Não é necessário trabalhar somente o filme em si, especialmente na sala de aula de LE (GARCIA-STEFANI, 2015).

Igualmente relevante é motivar a percepção de que o sucesso ou fracasso da aplicação do exercício didático não depende apenas do exercício em si, mas também, e principalmente, da abordagem do professor em relação ao material produzido, ou seja, como ele conduzirá a aplicação em sala de aula, daí a importância da troca de experiências entre professores para fomentar a percepção dessas ocorrências de sucesso ou fracasso. Muitas vezes, uma mesma atividade, aplicada pelo mesmo professor, seguindo as mesmas abordagens, em contextos diferentes, pode apresentar resultados diferentes quanto à sua aplicação.

A Teoria da Atividade prevê que a interação é uma das etapas para a aquisição do instrumento, juntamente com outras duas: demonstração e tentativa e erro (DUARTE, 2003).

Neste estudo, a aquisição do instrumento refere-se ao domínio da competência em desenvolver exercícios didáticos (EDs) com conteúdo fílmico. As etapas: demonstração, tentativa e erro e interação foram todas cumpridas ao longo do curso de formação, de maneira integrada e concomitante. As demonstrações eram feitas durante os momentos em que os professores cursistas apresentavam aos colegas e à professora-formadora as atividades que haviam preparado; nesses momentos os professores cursistas, por meio da interação com os demais colegas (que apontavam erros cometidos durante o processo de elaboração), tinham a oportunidade de tentar refazer o exercício proposto. Essas ações foram significativas para a evolução na aprendizagem sobre como desenvolver material de ensino com conteúdo fílmico.

No processo de aquisição do instrumento era importante que o professor vivenciasse, como aluno, aquilo que ele pretendia de seu alunado. $\mathrm{O}$ excerto a seguir denota a percepção da professora cursista sobre a importância de o professor colocar-se no lugar do aluno ao preparar e aplicar um exercício didático:

\footnotetext{
PP16 Celina (relatório final)

Como professores precisamos saber desenvolver e apresentar um conteúdo, mas, olhando a atividade como alunos, aprendemos a pensar sobre o que precisava ser alterado, o que poderia prejudicar a compreensão deles etc.
}

Percebemos, nas sessões de demonstração, a valorização das possibilidades de refazer, retocar, reestruturar o exercício didático, de modo a facilitar a compreensão e a aprendizagem. Aprendemos o que compreendemos. 
O processo de recomposição e reestruturação dos exercícios didáticos favorece, ainda, o desenvolvimento da autonomia do professor na aquisição do instrumento. Essas ações, mediadas pela interação, possibilitam ao professor usar seu conhecimento sobre como trabalhar didaticamente com o filme em qualquer situação de ensino (GARCIA-STEFANI, 2015), como ilustra o relato de Alice:

\begin{tabular}{|l|l|}
\hline $\begin{array}{l}\text { PP8- Alice } \\
\text { (relatório final) }\end{array}$ & $\begin{array}{l}{[\ldots] \text { melhor que dar o peixe, você nos ensinou a pescar, nos ensinou a }} \\
\text { desenvolvermos atividades com qualquer filme ou cena que julgarmos } \\
\text { interessante trabalhar com nossos alunos. [...] me senti orgulhosa por aplicar } \\
\text { atividades elaboradas por mim mesma e principalmente pela reação dos } \\
\text { alunos, que gostaram das mesmas, conseguiram realiza-las e disseram que } \\
\text { preferiam esse tipo de atividade a relatórios que professores costumavam } \\
\text { solicitar. [...] tudo o que posso dizer em relação ao curso é que contribuiu } \\
\text { significativamente para minha formação enquanto professora. }\end{array}$ \\
\hline
\end{tabular}

O relato de Alice evidencia um sentimento de realização da professora pelo fato de ela própria ter desenvolvido os exercícios didáticos, e ter constatado que a aplicação do exercício em sala de aula foi satisfatória. A professora cursista constata que é parte ativa em todo o processo: de preparação do exercício, da análise do exercício concluído, da aplicação em sala de aula e da avaliação do resultado dessa aplicação. Sua prática pedagógica é (re)avaliada por ela mesma durante todo o processo. Isso a habilita para trabalhar com outros filmes, em outros contextos.

É importante mencionar que o fato de o professor constatar a reação positiva do aluno ao realizar uma atividade proposta por ele eleva sua autoestima, principalmente quando o estudante manifesta preferência por aulas desse tipo.

A valorização da interação, suscitada no curso de formação continuada, ocorreu não somente entre os professores participantes do curso, mas também entre eles e seus alunos, como relata Rosa:

\begin{tabular}{|l|l|}
\hline $\begin{array}{l}\text { PP12 - Rosa } \\
\text { (relatório final) }\end{array}$ & $\begin{array}{l}\text { (...) possibilitou também um trabalho interdisciplinar. (...) Foi uma experiência } \\
\text { muito positiva, pois promoveu a participação, envolvimento e interação dos } \\
\text { alunos. E os alunos entenderam que ao trabalhar com um filme na disciplina de } \\
\text { Língua Estrangeira é possível também promover a articulação entre o Inglês e } \\
\text { outras disciplinas.(...). }\end{array}$ \\
\hline
\end{tabular}

Além da valorização da aprendizagem por meio da interação, Rosa destaca, ainda, a importância de promover a interdisciplinaridade no trabalho com cinema em sala de aula algo que já enfatizávamos desde o início do curso de formação. 


\section{Principais contribuições do curso de formação}

De acordo com dados obtidos no estudo, o curso de formação continuada contribuiu para: 1) Desenvolvimento da criatividade na execução das ações individuais e coletivas para a preparação de material de ensino com conteúdo fílmico; 2) Aumento da percepção sobre a maneira como o aluno aprende; 3) Estímulo para a apreciação da sétima arte; 4) Ampliação das possiblidades de trabalho pedagógico com cinema; 5) Reconhecimento da importância de ensinar com motivação; 6) Reconhecimento da importância da reflexão sobre a prática pedagógica; 7) Ampliação da capacidade de análise de material didático; 8) Valorização da aprendizagem por meio da interação e colaboração entre os pares; 9) Ampliação das possibilidades de utilizar diferentes abordagens de ensino em diferentes contextos; 10) Percepção da importância do desenvolvimento da autonomia no aprendizado; e 11) Aumento da dinamicidade nas aulas de LE (GARCIA-STEFANI, 2015).

A proposta do curso de formação foi integrar os professores na experiência de novas práticas, ao invés de prescrever métodos e abordagens de ensino aos quais devem apenas "ajustar-se" ou "adaptar-se", como ainda vemos em muitos cursos de formação continuada (UYENO, 2002). Não queríamos que o professor agisse como mero aplicador de teorias (UYENO, 2002); por isso preocupamo-nos em oferecer, além dos subsídios teóricos necessários para a preparação de atividades didáticas com conteúdo fílmico, oportunidades tanto de praticar a teoria quanto de discutir, conjunta e interativamente, os resultados da prática. Dessa forma teríamos dados mais confiáveis sobre os resultados da utilização do cinema como ferramenta de ensino de língua estrangeira. Nessa perspectiva, a integração do professor no seu próprio processo de formação, foi primordial. De acordo com FREIRE (1999):

Insistimos, em todo o corpo de nosso estudo, na integração e não na acomodação, como atividade da órbita puramente humana. A integração resulta da capacidade de ajustar-se à realidade acrescida da de transformá-la a que se junta a de optar, cuja nota fundamental é a criticidade. Na medida em que o homem perde a capacidade de optar e vai sendo submetido a prescrições alheias que o minimizam e as suas decisões já não são suas, porque resultadas de comandos estranhos, já não se integra. Acomoda-se. Ajusta-se. O homem integrado é o homem Sujeito. A adaptação é assim um conceito passivo - a integração ou comunhão, ativo (FREIRE, 1999, p. 42). 
O trecho transcrito da obra de Paulo Freire denota a importância de promover a integração, como forma de viabilizar a transformação e o desenvolvimento da criticidade. Essa foi uma das metas deste estudo, de caráter interventivo: promover um ambiente de formação continuada para dar voz ao professor, onde ele pudesse ter oportunidade de conhecer novas práticas, além de opinar e refletir sobre suas próprias ações pedagógicas e sobre as ações dos demais companheiros de trabalho. Nesse sentido, o processo de interação e compartilhamento de experiências vivenciado no curso de formação continuada foi fundamental para a aprendizagem sobre como explorar o filme didaticamente, de maneira significativa, na aula de língua estrangeira

É elementar que cursos de formação continuada de professores, além de subsidiá-los com teorias e práticas que permeiam o contexto de formação, lhes possibilitem refletir sobre sua prática, não somente no sentido de pensar sobre, mas no sentido de transformá-la (GARCIA-STEFANI, 2015, p.157).

Este estudo desenvolveu-se com o propósito de intervenção para a transformação. Os alunos do século XXI já não são os mesmos do século XX, mas ainda vivenciamos práticas pedagógicas do século XIX. É preciso não somente transformar, mas revolucionar, para adequar o processo de ensino e aprendizagem aos desafios do novo século.

O ensino só será revolucionário quando permitir que alunos e professores sejam agentes transformadores de suas condições de existência, promovendo a expansão do pensamento e a (re)significação das suas experiências.

\section{Referências}

ALMEIDA, M. J. Imagens e sons: a nova cultura oral. São Paulo: Cortez, 2000. BRASIL. Orientações Curriculares para o Ensino Médio. Brasília: MEC/SEB, v.1, 2006.

CIPOLINI, A. Não é fita, é fato: tensões entre instrumento e objeto: um estudo sobre a utilização do cinema na educação. 2008. Dissertação (Mestrado). Universidade de São Paulo, 2008.

CLOT, Y. A função psicológica do trabalho. Petrópolis: Vozes, 2007.

CRUZ, M.L.O.B.; SOUZA, F.M.; LIMA, L.F.M. Aquisição linguístico-cultural de Espanhol-Língua estrangeira (E-LE) mediada pelo cinema: um estudo de representações. In: DE PINHO, S.Z.; SAGLIETTI, J.R.C. (org.). Livro eletrônico dos Núcleos de ensino da UNESP. São Paulo: Ed. Unesp, 2006, p. 957-964.

DANIELS, H. Cultural historical activity theory and professional learning. International journal of disability, development and education, v. 51, n. 2, 2004, p. 185-200.

DANIELS, H. Vygotsky and pedagogy. Routledge, 2002. 
DANIELS, H. Activity theory, discourse and Bernstein. Educational Review, v. 56, n. 2, 2004, p. 121-132.

DUARTE, N. A teoria da atividade como uma abordagem para a pesquisa em educação. Perspectiva, v. 21, n. 2, 2003, p. 279-301.

EDWARDS, A. From the systemic to the relational: relational agency and activity theory. In: SANNINO, A.; DANIELS, H.; GUTIÉRREZ, K. (Ed.). Learning and expanding with activity theory. Cambridge University Press, 2009, p. 197-211.

ENGESTRÖM, Y. Expansive Learning: Toward an Activity-Theoretical Reconceptualization. In Knud Illeris (Ed.). Contemporary Theories of Learning: Learning Theorists: in Their Own Words. Routledge. 2009.

Activity Theory and individual and social transformation. In: ENGESTRÖM, Y; MIETTINEM, R.; PUNAMAKI, R. (Ed.) Perspectives on activity theory. Cambridge University Press, 1999, p. 19-38.

FIORENTINI, L. M. R. TV na Escola e os Desafios de Hoje: Curso de Extensão para Professores do Ensino Fundamental e Médio da Rede Pública UniRede e Seed/MEC.

FIORENTINI, L. M. R; CARNEIRO, V. L. Q. (Org.). 2. ed. Brasília: Ed. Universidade de Brasília, 2002.

FREIRE, Paulo. Educação como prática da liberdade. Rio de Janeiro: Paz e Terra, 1999.

GARCIA STEFANI, V. C. O cinema na aula de língua estrangeira: uma proposta didáticopedagógica para o ensino-aprendizagem de espanhol. 2010. Dissertação (Mestrado). São Carlos: UFSCar.

Formação continuada de professores de línguas estrangeiras mediada pelo cinema: contribuições da teoria da atividade. 2015. Tese (Doutorado). São Carlos: UFSCar,

GEE, J. P. New times and new literacies. In: BALL, A.; FREEDMAN, S., W. (org). Bakhtinian Perspectives on Language, Literacy, and Learning. Cambridge, 2004.

GEE, J. P. Bons videogames e boa aprendizagem. Perspectiva, v. 27, n. 1, 2009, p. 167-178.

GOYES NARVÁEZ, J. C. Horizonte de la comunicación visual contemporánea. In:

Espéculo Revista de estudios literarios. Universidad Complutense de Madrid, 2002.

Disponível em: http://www.ucm.es/info/especulo/numero22/com_visu.html. Acesso em: set. 2009.

HARLOW, L. L.; MUYSKENS, J. A. Priorities for intermediate-level language instruction. Modern Language Journal, n. 78, 1994, p. 141-154.

IERVOLINO, S.A.; PELICIONI, MCF. A utilização do grupo focal como metodologia qualitativa na promoção da saúde. Rev. Esc. Enf. USP, v. 35, n.2, p.115-21, jun. 2001. Disponível em http://www.scielo.br/pdf/reeusp/v35n2/v35n2a03.pdf. Acesso em: nov. 2009. 
LEFFA, V. J. Aprendizagem mediada por computador à luz da Teoria da Atividade. In: Calidoscópio, v. 3, n. 1, 2005, p. 21-30.

LEONTIEV, A. N. Activity, consciousness and personality. Englewood Cliffs: PrenticeHall, 1978.

LURIA, A. R.; YODOCICH, F. I. O papel da linguagem na formação de processos mentais: colocação do problema. In: LURIA, A. R.; YODOCICH, F. I. Linguagens e

desenvolvimento intelectual na criança. Porto Alegre: Artes Médicas, 1985, p. 7-23.

MAGALHÃES, M. C. C. O professor de línguas como pesquisador de sua ação: a pesquisa colaborativa. Trajetórias na formação de professores de línguas. Londrina: UEL, 2002. p. $39-58$.

MATEUS, E.; EL KADRI, M. S. Práticas significativas no ensino e na formação de professores/as de inglês: recriando realidades por meio do estágio no Programa Institucional de Bolsa de Iniciação à Docência. In: LIBERALI, F. C.; MATEUS, E.; DAMIANOVIC, M. C. (org.). A Teoria da Atividade Sócio Histórico-Cultural e a escola: recriando realidades sociais. Campinas: Pontes, 2012. p. 109-135.

MAYRINK, M. F. Luzes... Câmera... Refexão: formação inicial de professores mediada por filmes. 2007. 300 f. Tese (Doutorado)-Programa de estudos pós-graduados em Linguística Aplicada e Estudos da linguagem. Pontifícia Universidade Católica de São Paulo, 2007.

MIRANDA, C. E. A.; COPPOLA, G. D.; RIGOTTI, G. F. A educação pelo cinema. Rev. Educação e Cinema, Unicamp: SP, p. 02, 2005.

NAPOLITANO, M. Como usar o cinema na sala de aula. São Paulo: Contexto, 2003.

PÉREZ TOBARRA, Luis. El corto en la clase de ELE. Dos propuestas de explotación didáctica de cortos. Problemas de comunicación"". Revista Electrónica de Didáctica del Español como Lengua Extranjera [en línea], v. 10, 2007.

SÃO PAUlO (Estado). Secretaria da Educação. Currículo do Estado de São Paulo: Linguagens, códigos e suas tecnologias. São Paulo: SEE, 2010.

STEPHENS, J. L. Teaching culture and improving language skills through a cinematic lens: a course on spanish film in the undergraduate Spanish curriculum. In: ADFL Buletin, v. 33, n. 1, p. 22-25, 2001. Disponível em: http://web2.adfl.org/ADFL/bulletin/v33n1/331022.htm. Acesso em: 26 set. 2009.

TORRECILLAS, A. B.; SÁNCHEZ, M. A. T. El estimulo cinematográfico: desarrollo de destrezas comunicativas y valor cultural. Centro de Lenguas modernas, Universidad de Granada, 1993. p. 537-551.

UYENO, E. Y. A dogmatização da teoria: a contradição como negação da falta no discurso do professor de línguas. 2002. Tese (Doutorado). Instituto de Estudos da Linguagem.

Unicamp: Campinas. 
VIEIRA-ABRAHÃO, Maria Helena Vieira. A formação do professor de línguas de uma perspectiva sociocultural. Signum- Estudos de Linguagem, 2012, p. 457-480.

VYGOTSKY, L.S. A formação social da mente. $4^{\mathrm{a}}$ ed. São Paulo: Martins Fontes, 1991. . Pensamento e linguagem. São Paulo: Martins Fontes, 1993.

VYGOTSKY, L.; LURIA, A.; LEONTIEV, A. Linguagem, desenvolvimento e aprendizagem. São Paulo: Ícone. 1988.

WENGER, E. Communities of practice: learning meaning and identity. Cambridge: Cambridge University Press, 1998. 